\title{
Article
}

\section{Reference Percentiles for Bioelectrical Phase Angle in Athletes}

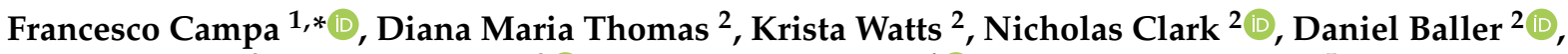 \\ Thomas Morin $^{2}$, Stefania Toselli ${ }^{3}{ }^{\circledR}$, Josely Correa Koury $\left.{ }^{4}{ }^{(}\right)$, Giovanni Melchiorri ${ }^{5}$, Angela Andreoli ${ }^{5}{ }^{(0)}$, \\ Gabriele Mascherini ${ }^{6}{ }^{\circ}$, Cristian Petri ${ }^{7}$, Luis Bettencourt Sardinha ${ }^{8}$ and Analiza Monica Silva ${ }^{8}(\mathbb{0}$
}

1 Department for Life Quality Studies, University of Bologna, 47921 Rimini, Italy

2 Department of Mathematical Sciences, United States Military Academy, West Point, NY 10996, USA; diana.thomas@westpoint.edu (D.M.T.); krista.watts@westpoint.edu (K.W.); nicholas.clark@westpoint.edu (N.C.); daniel.baller@westpoint.edu (D.B.); thomas12vm@gmail.com (T.M.)

3 Departments of Biomedical and Neuromotor Sciences, University of Bologna, 40121 Bologna, Italy; stefania.toselli@unibo.it

4 Department of Basic and Experimental Nutrition, Nutrition Institute, State University of Rio de Janeiro, Rio de Janeiro 20550-900, Brazil; jckoury@gmail.com

5 Department of Systems Medicine, University of Tor Vergata, 00175 Rome, Italy; gmelchiorri@libero.it (G.M.); angela.andreoli@uniroma2.it (A.A.)

6 Department of Experimental and Clinical Medicine, University of Florence, 50134 Florence, Italy; gabriele.mascherini@unifi.it

7 Department of Sports and Computer Science, Section of Physical Education and Sports, Universidad Pablo de Olavide, 41013 Seville, Spain; cpet2@alu.upo.es

8 Exercise and Health Laboratory, CIPER, Faculdade de Motricidade Humana, Universidade de Lisboa, 1499-002 Cruz Quebrada, Portugal; lbsardinha55@gmail.com (L.B.S.); analiza@fmh.ulisboa.pt (A.M.S.)

* Correspondence: francesco.campa3@unibo.it

check for updates

Citation: Campa, F.; Thomas, D.M.; Watts, K.; Clark, N.; Baller, D.; Morin, T.; Toselli, S.; Koury, J.C.; Melchiorri, G.; Andreoli, A.; et al. Reference Percentiles for Bioelectrical Phase Angle in Athletes. Biology 2022, 11, 264. https://doi.org/10.3390/ biology11020264

Received: 19 January 2022 Accepted: 7 February 2022 Published: 8 February 2022

Publisher's Note: MDPI stays neutral with regard to jurisdictional claims in published maps and institutional affiliations.

Copyright: (C) 2022 by the authors. Licensee MDPI, Basel, Switzerland. This article is an open access article distributed under the terms and conditions of the Creative Commons Attribution (CC BY) license (https:// creativecommons.org/licenses/by/ $4.0 /)$.
Simple Summary: The bioelectrical phase angle is a raw parameter that can be utilized as an indicator of performance, muscle quantity and hydration status of cells. However, sex- and sport-specific phase angle reference percentiles are lacking for the athletic population. For the first time, this study provides 5th, 15th, 50th, 85th, and 95th reference percentiles for phase angle in male and female athletes practicing different sports. These reference values can be used to track body composition and performance related-outcomes in sports practice, while leveraging the portability of bioelectric impedance analysis.

\begin{abstract}
The present study aimed to develop reference values for bioelectrical phase angle in male and female athletes from different sports. Overall, 2224 subjects participated in this study [1658 males (age $26.2 \pm 8.9$ y) and 566 females (age $26.9 \pm 6.6$ y)]. Participants were categorized by their sport discipline and sorted into three different sport modalities: endurance, velocity/power, and team sports. Phase angle was directly measured using a foot-to-hand bioimpedance technology at a $50 \mathrm{kHz}$ frequency during the in-season period. Reference percentiles (5th, 15th, 50th, 85th, and 95th) were calculated and stratified by sex, sport discipline and modality using an empirical Bayesian analysis. This method allows for the sharing of information between different groups, creating reference percentiles, even for sports disciplines with few observations. Phase angle differed (men: $p<0.001$; women: $p=0.003$ ) among the three sport modalities, where endurance athletes showed a lower value than the other groups (men: vs. velocity/power: $p=0.010,95 \% \mathrm{CI}=-0.43$ to -0.04 ; vs. team sports: $p<0.001,95 \% \mathrm{CI}=-0.48$ to -0.02 ; women: vs. velocity/power: $p=0.002,95 \% \mathrm{CI}=-0.59$ to -0.10 ; vs. team sports: $p=0.015,95 \% \mathrm{CI}=-0.52$ to -0.04$)$. Male athletes showed a higher phase angle than female athletes within each sport modality (endurance: $p<0.01,95 \% \mathrm{CI}=0.63$ to 1.14 ; velocity/power: $p<0.01,95 \% \mathrm{CI}=0.68$ to 1.07 ; team sports: $p<0.01,95 \% \mathrm{CI}=0.98$ to 1.23 ). We derived phase angle reference percentiles for endurance, velocity/power, and team sports athletes. Additionally, we calculated sex-specific references for a total of 22 and 19 sport disciplines for male and female athletes, respectively. This study provides sex- and sport-specific percentiles for phase angle that can track body composition and performance-related parameters in athletes.
\end{abstract}


Keywords: BIA; body composition; fat-free mass; endurance; sports performance; team sports

\section{Introduction}

Body composition assessment is an important practice in sports management, given the numerous implications on health and physical performance [1]. Several compartments of body composition are predictors of health and sports performance outcomes [1]. For example, a higher percent body fat is negatively related with the quality of movement and physical performance, in particular sports that require sprinting or jumping [2]. Additionally, muscle mass contributes to the production of strength and power [3] and total body water influences neuromuscular, as well as cognitive functions [4-6]. The most accurate body composition assessment evaluations depend on specialized laboratory based methods, such as magnetic resonance imaging, isotope dilution techniques, dual-energy $\mathrm{X}$-ray absorptiometry, and air plethysmography [7]. These laboratory-based body composition assessments quantify tissue (e.g., lean soft and skeletal muscle tissues) and molecular-level (e.g., total body water) body composition elements. However, the amount of specialized training required, high cost, and time-burden to athletes being measured make such methods unfeasible for routine application by coaches, trainers or other sports managers [7].

Due to the portability and ease of application, the use of the bioelectrical impedance analysis (BIA) has been increasing in sports practice especially because current studies have revealed that when following standardized protocols for BIA assessment, body composition measurements are comparable to more sophisticated clinical methods [7-10]. In addition, BIA yields additional raw bioelectrical parameters that can be independently used to qualitatively track body composition $[7,8]$. Particularly, bioelectrical resistance and reactance, the two components of impedance, are associated with body fluid content and cell density, respectively [11]. The bioelectrical phase angle, which is the arctangent of reactance divided by resistance, has been identified as a biomarker of muscle quantity and predicts the intracellular-to-extracellular water ratio in athletes $[7,8]$. In particular, high phase angle values are associated with subjects who have high muscle mass and a higher content of intracellular than extracellular fluids [12-14]. In the context of sports, changes in phase angle are associated with physical adaptations obtainable after training or nutritional interventions [8]. Furthermore, recent findings have highlighted the phase angle's positive association with sport-specific muscle strength and power test outcomes [15-17].

The relationships between phase angle and body composition have led to a call for methods that leverage phase angle data to track athletic performance and health over a season [18]. To date, reference phase angle values are available for the general and elderly population [19-23]. However, to the best of our knowledge, reference phase angle percentiles for athletes do not exist. To fill this gap, the present study aimed to develop sexand sport-specific phase angle reference percentiles for athletes.

\section{Materials and Methods}

\subsection{Participants and Study Design}

This cross-sectional study involved 2224 national athletes assessed in the in-season period and including 1658 males (age $26.2 \pm 8.9$ y) and 566 females (age $26.9 \pm 6.6 \mathrm{y}$ ) of 22 and 19 different sport disciplines, respectively. The following inclusion criteria were used: (i) aged $16 \mathrm{y}$ or older; and (ii) not injured or ill at the moment of the test. Similar to previous studies [1,24], the participants were sorted into three groups of sport modalities: endurance (cycling, marathon, pentathlon, sailing, ski, rowing, and triathlon), velocity / power (athletics including jumping, throwing, short-distance running; badminton; boxing; judo; karate; kickboxing; rhythmic gymnastics; swimming including short-distance swimming; and tennis), and team sports (basketball, field hockey, handball, rugby, soccer, volleyball, and water polo). Since they cannot be considered as athletes [18], soccer referees and CrossFit exercisers were not included in any of the three sports modalities. All subjects 
were informed of the study design before giving written informed consent to participate. As sample sizes within some sports were low, percentiles were estimated using a parametric and empirical Bayesian framework that allowed for information sharing between sports. All procedures were approved by the bioethics committee of the University of Bologna and were conducted in accordance with the declaration of Helsinki for human studies (Ethical Approval Code: 25027; dated 13 March 2017).

\subsection{Procedures}

All measurements were performed in resting conditions (9.00 AM) following standard procedures suggested for athletes $[7,25]$. Height was measured to the nearest $0.1 \mathrm{~cm}$ using a stadiometer. Body weight was determined to the nearest $0.1 \mathrm{~kg}$, using a mechanical scale (Seca 711, Seca, Hamburg, Deutschland). Body mass index (BMI) was calculated as total body mass (kilograms) divided by height (meters) squared. BIA was performed according with standardized procedures specific for athletes [9]. The bioelectrical phase angle was directly measured with BIA (BIA 101, Akern, Florence, Italy), which applies an alternating current of $800 \mu \mathrm{A}$ at a single frequency of $50 \mathrm{kHz}$. Fat-free mass (FFM) (kilograms) was estimated using a specific equation for athletes [26] and FFM index (FFMI) calculates as FFM divided by height (meters) squared.

\subsection{Statistical Analysis}

Statistical analyses were performed using the R software (version 4.1.0). Analyses were performed to complete two tasks: (i) estimate the reference percentiles for phase angle, stratified by sex and sport; (ii) test whether the mean for each outcome differed by sex and sport modalities. To create reference percentiles, an empirical Bayesian analysis was performed [27]. Empirical Bayesian analysis allows the sharing of information across sports to augment our inference whenever we had at least two athletes' values. This allows estimates for sports where there are only a few participants. In order to conduct the analysis, both a sampling distribution as well as a prior distribution for the parameters of the sampling distribution must be specified. Within a given sex and sport, the athletes' outcome values were assumed to follow a normal (Gaussian) distribution that could be characterized through its mean and precision (inverse variance). This assumption is supported based on the sample distributions, as showed in Figure 1. If the mean and precision were known, all quantiles followed immediately from the normal assumption. The sport-specific means and variances were modelled as arising from a normal-gamma distribution, which serves as the prior and forms a conjugate family with our observational model. The hyperparameters of the prior were informed empirically through maximumlikelihood by using all athletes' data for this outcome, restricted by sex. Once this was carried out, joint posterior distributions for the mean and precision were generated for every sport, giving rise to point estimates and $95 \%$ joint confidence regions for the mean and precision, which in turn were used to calculate simultaneous $95 \%$ confidence intervals for the reference percentiles of interest. Percentiles (5th, 15th, 50th, 85th, and 95th) were presented for all sports/sex subgroups. Sex and sport modality comparisons for phase angle and FFMI were performed with unpaired t-tests or analysis of variance with Bonferroni post-hoc. Statistical significance was predetermined as $p<0.05$. Cohen's d effect size (ES) with $95 \%$ confidence interval $(\mathrm{CI})$ was reported for significant between-sex comparisons and interpreted according to the following Hopkins' recommendations: 0-0.19: trivial; 0.20-0.59: small; 0.60-1.19: moderate; $1.20-1.99$ : large; $\geq 2.00$ : very large [28]. 

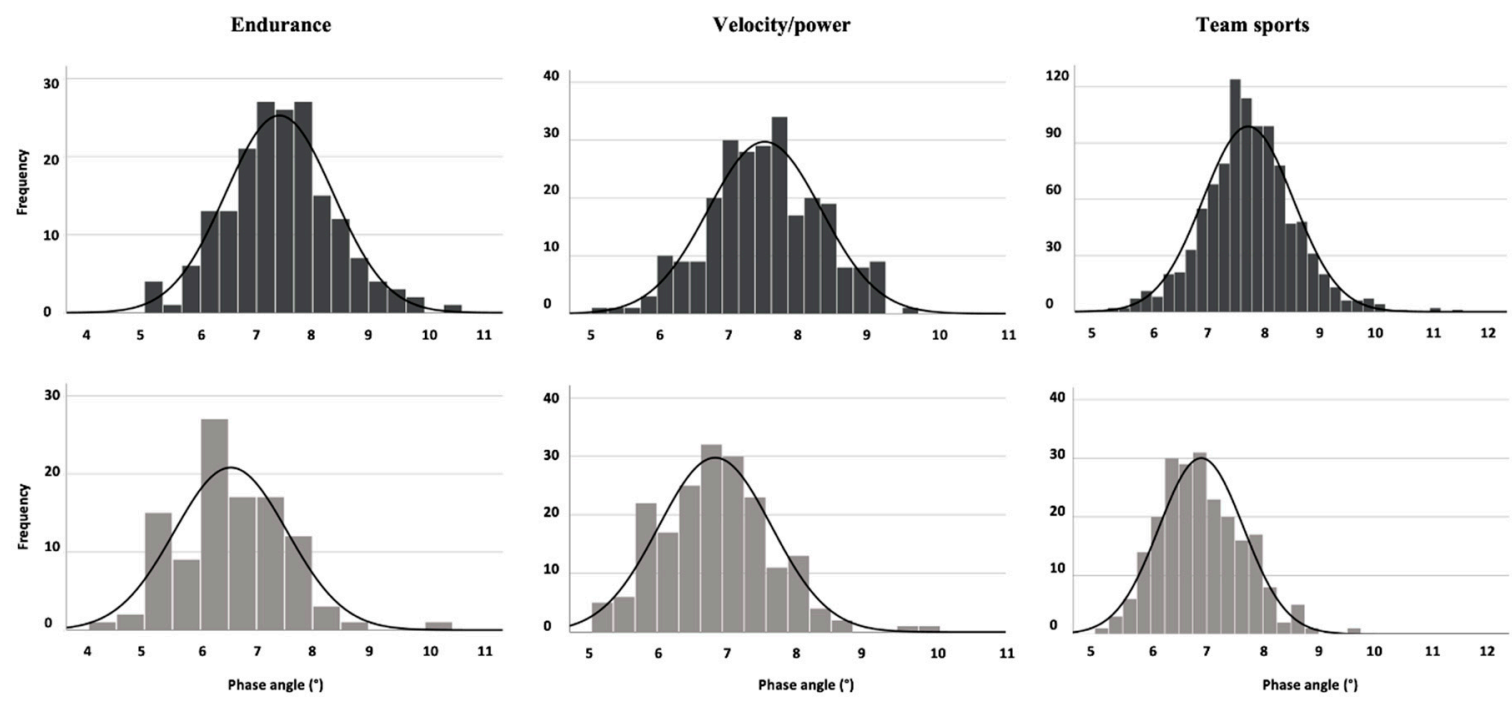

Figure 1. Phase angle distribution by sport modality and sex, with men and women in upper and lower panels, respectively.

\section{Results}

Table 1 presents the data summary for each sport discipline.

Table 1. Participants' data summary.

\begin{tabular}{cccc}
\hline & Men & \multicolumn{2}{c}{ Women } \\
\hline Sport Discipline & N (\% of Total) & Sport Discipline & N (\% of Total) \\
\hline Overall & $1658(100 \%)$ & Overall & $566(100 \%)$ \\
Athletics & $47(2.8 \%)$ & Athletics & $19(3.4 \%)$ \\
Badminton & $7(0.4 \%)$ & Badminton & $4(0.7 \%)$ \\
Basket & $85(5.1 \%)$ & Basket & $55(9.7 \%)$ \\
CrossFit & $61(3.7 \%)$ & Boxing & $9(1.6 \%)$ \\
Cyclists & $15(0.9 \%)$ & CrossFit & $41(7.2 \%)$ \\
Field Hockey & $12(0.7 \%)$ & Gymnastics & $25(4.4 \%)$ \\
\hline Handball & $40(2.4 \%)$ & Handball & $4(0.7 \%)$ \\
Judo & $53(3.2 \%)$ & Judo & $23(4.1 \%)$ \\
Karate & $28(1.7 \%)$ & Karate & $5(0.9 \%)$ \\
Kick-boxing & $48(2.9 \%)$ & Kick-boxing & $20(3.5 \%)$ \\
Marathon & $80(4.8 \%)$ & Marathon & $53(9.4 \%)$ \\
Pentathlon & $32(1.9 \%)$ & Pentathlon & $20(3.5 \%)$ \\
\hline Rugby & $147(8.9 \%)$ & Rowing & $13(2.3 \%)$ \\
Sailing & $2(0.1 \%)$ & Soccer & $55(9.7 \%)$ \\
Ski & $4(0.2 \%)$ & Swimming & $46(8.1 \%)$ \\
Soccer & $490(29.6 \%)$ & Tennis & $42(7.4 \%)$ \\
Soccer referees & $149(9.0 \%)$ & Triathlon & $20(3.5 \%)$ \\
Swimming & $49(3.0 \%)$ & Volleyball & $94(16.6 \%)$ \\
Tennis & $25(1.5 \%)$ & Waterpolo & $18(3.2 \%)$ \\
Triathlon & $51(3.1 \%)$ & & \\
Volleyball & $174(10.5 \%)$ & & \\
Waterpolo & $59(3.6 \%)$ & & \\
\hline & & & \\
\hline
\end{tabular}

Table 2 shows the general characteristics for the athletes grouped by sex and sport modality. Phase angle differed (men: $p<0.001$; women: $p=0.003$,) among the three sport modalities, where endurance athletes showed a lower value than the other groups (men: vs. velocity/power: $p=0.010$; vs. team sports: $p<0.001$; women: vs. velocity/power: $p=0.002$; vs. team sports: $p=0.015$ ). Male athletes showed a higher phase angle than female athletes within each sport modality (endurance: $p<0.01$, $\mathrm{ES}=0.88,95 \% \mathrm{CI}=0.63$ 
to 1.14; velocity / power: $p<0.01, \mathrm{ES}=0.88,95 \% \mathrm{CI}=0.68$ to 1.07 ; team sports: $p<0.01$, $\mathrm{ES}=1.12,95 \% \mathrm{CI}=0.98$ to 1.23$)$.

Significant differences were found for FFMI among sport modalities (men: $p=0.002$; women: $p=0.025)$. Endurance showed a mean FFMI value lower than velocity/power (men: $p=0.033$; women: $p=0.048$ ) and team sports athletes (men: $p=0.001$; women: $p=0.038$ ). Male athletes showed a higher FFMI than female athletes within each sport modality (endurance: $p<0.01, \mathrm{ES}=2.21,95 \% \mathrm{CI}=1.82$ to 2.41 ; velocity / power: $p<0.01$, $\mathrm{ES}=1.80,95 \% \mathrm{CI}=1.55$ to 2.04 ; team sports: $p<0.01, \mathrm{ES}=1.59,95 \% \mathrm{CI}=1.44$ to 1.74 ).

Table 2. Body composition characteristics of the athletes according to sport modality.

\begin{tabular}{|c|c|c|c|c|c|c|c|c|}
\hline & $\mathbf{N}$ & Age (y) & $\begin{array}{l}\text { Weight } \\
\text { (kg) }\end{array}$ & $\begin{array}{l}\text { Height } \\
\text { (cm) }\end{array}$ & $\begin{array}{c}\text { BMI } \\
\left(\mathrm{kg} / \mathrm{m}^{2}\right)\end{array}$ & FFM (kg) & $\begin{array}{c}\text { FFMI } \\
\left(\mathrm{kg} / \mathrm{m}^{2}\right)\end{array}$ & $\begin{array}{c}\text { Phase } \\
\text { Angle }\left({ }^{\circ}\right)\end{array}$ \\
\hline \multicolumn{9}{|l|}{ Men } \\
\hline Endurance & 182 & $27.9(11.4)$ & $70.6(8.9)$ & $175.5(6.4)$ & $22.9(2.5)$ & $61.7(6.5)$ & $20.0(1.7)$ & $7.4(0.9)$ \\
\hline Velocity/power & 257 & $25.6(9.9)$ & $73.4(10.6)$ & $177.2(7.8)$ & $23.2(2.5)$ & $65.3(8.5)$ & $20.6(2.2)$ & $7.6(0.9)$ \\
\hline Team sports & 1007 & $23.6(6.1)$ & 80.9 (13.4) & $184.1(9.6)$ & $23.9(3.8)$ & $70.4(10.6)$ & $20.7(2.6)$ & $7.7(0.8)$ \\
\hline \multicolumn{9}{|l|}{ Women } \\
\hline Endurance & 106 & $33.6(13.1)$ & $60.6(7.9)$ & $166.3(8.1)$ & $21.9(2.6)$ & $45.4(6.0)$ & $16.2(1.4)$ & $6.5(1.0)$ \\
\hline Velocity/power & 213 & $27.8(10.2)$ & $61.5(9.2)$ & $166.9(6.8)$ & $21.9(2.2)$ & 47.5 (7.5) & $17.2(1.7)$ & $6.9(0.9)$ \\
\hline Team sports & 227 & $28.0(7.0)$ & $67.2(9.2)$ & $174.1(10.0)$ & $22.1(2.2)$ & $51.5(7.2)$ & $17.0(1.6)$ & $6.8(0.8)$ \\
\hline
\end{tabular}

Note: Data are reported as mean (standard deviation); BMI: body mass index; FFM: fat-free mass; FFMI: fat-free mass index.

The sport and sex derived reference percentiles 5th, 15th, 50th, 85th, and 95th for phase angle values by sport disciplines and modalities are reported in Tables 3 and 4 for men and women, respectively.

Table 3. Phase Angle reference percentiles for men.

\begin{tabular}{|c|c|c|c|c|c|}
\hline Sport Discipline & 5 th $(95 \%$ CI $)$ & 15th $(95 \% \mathrm{CI})$ & 50th $(95 \% \mathrm{CI})$ & 85th $(95 \% \mathrm{CI})$ & 95th $(95 \%$ CI $)$ \\
\hline Athletics & $6.3(6.2,6.3)$ & $6.8(6.7,6.8)$ & $7.7(7.6,7.7)$ & $8.6(8.5,8.6)$ & $9.1(9.0,9.1)$ \\
\hline Badminton & $6.2(6.1,6.3)$ & $6.8(6.7,6.9)$ & $7.6(7.6,7.7)$ & $8.5(8.4,8.6)$ & $9.0(8.9,9.1)$ \\
\hline Basketball & $6.3(6.2,6.3)$ & $6.8(6.7,6.8)$ & $7.6(7.6,7.7)$ & $8.5(8.4,8.6)$ & $9.0(8.9,9.1)$ \\
\hline CrossFit & $6.3(6.2,6.3)$ & $6.8(6.7,6.8)$ & $7.6(7.6,7.7)$ & $8.5(8.4,8.6)$ & $9.0(8.9,9.1)$ \\
\hline Cyclists & $6.3(6.2,6.4)$ & $6.8(6.7,6.9)$ & $7.6(7.6,7.7)$ & $8.5(8.4,8.6)$ & $9.0(8.9,9.1)$ \\
\hline Field hockey & $6.3(6.2,6.4)$ & $6.8(6.7,6.9)$ & $7.6(7.6,7.7)$ & $8.5(8.4,8.6)$ & $9.0(8.9,9.1)$ \\
\hline Handball & $6.3(6.2,6.4)$ & $6.8(6.7,6.9)$ & $7.7(7.6,7.7)$ & $8.5(8.5,8.6)$ & $9.0(8.9,9.1)$ \\
\hline Judo & $6.3(6.2,6.4)$ & $6.8(6.7,6.9$ & $7.6(7.6,7.7)$ & $8.5(8.4,8.6)$ & $9.0(8.9,9.1)$ \\
\hline Karate & $6.3(6.2,6.4)$ & $6.8(6.7,6.9)$ & $7.6(7.6,7.7)$ & $8.5(8.4,8.6)$ & $9.0(8.9,9.1)$ \\
\hline Kick-boxing & $6.3(6.2,6.3)$ & $6.8(6.7,6.8)$ & $7.6(7.6,7.7)$ & $8.5(8.4,8.5)$ & $9.0(8.9,9.1)$ \\
\hline Marathon & $6.3(6.2,6.3)$ & $6.8(6.7,6.8)$ & $7.6(7.6,7.7)$ & $8.5(8.4,8.5)$ & $9.0(8.9,9.1)$ \\
\hline Pentathlon & $6.3(6.2,6.4)$ & $6.8(6.7,6.8)$ & $7.6(7.6,7.7)$ & $8.5(8.4,8.6)$ & $9.0(8.9,9.1)$ \\
\hline Rugby & $6.3(6.2,6.4)$ & $6.8(6.7,6.9)$ & $7.6(7.6,7.7)$ & $8.5(8.4,8.6)$ & $9.0(8.9,9.1)$ \\
\hline Sailing & $6.3(6.2,6.4)$ & $6.8(6.7,6.9)$ & $7.6(7.6,7.7)$ & $8.5(8.4,8.6)$ & $9.0(8.9,9.1)$ \\
\hline Ski & $6.3(6.2,6.4)$ & $6.7(6.7,6.9)$ & $7.7(7.6,7.7)$ & $8.5(8.4,8.6)$ & $9.0(8.9,9.1)$ \\
\hline Soccer & $6.3(6.2,6.4)$ & $6.8(6.7,6.9)$ & $7.6(7.6,7.7)$ & $8.5(8.4,8.6)$ & $9.0(8.9,9.1)$ \\
\hline Soccer referees & $6.3(6.2,6.3)$ & $6.8(6.8,6.8)$ & $7.6(7.6,7.7)$ & $8.5(8.5,8.6)$ & $9.0(8.9,9.1)$ \\
\hline Swimming & $6.3(6.2,6.4)$ & $6.8(6.7,6.9)$ & $7.6(7.6,7.7)$ & $8.5(8.4,8.6)$ & $9.0(9.0,8.9)$ \\
\hline Tennis & $6.3(6.2,6.4)$ & $6.8(6.7,6.9)$ & $7.6(7.6,7.7)$ & $8.5(8.4,8.6)$ & $9.0(8.9,9.1)$ \\
\hline Triathlon & $6.3(6.2,6.4)$ & $6.8(6.7,6.9)$ & $7.7(7.6,7.7)$ & $8.5(8.4,8.6)$ & $9.0(8.9,9.1)$ \\
\hline Volleyball & $6.3(6.2,6.4)$ & $6.8(6.7,6.9)$ & $7.6(7.6,7.7)$ & $8.5(8.4,8.5)$ & $8.9(8.9,9.0)$ \\
\hline Waterpolo & $6.3(6.2,6.4)$ & $6.8(6.7,6.9)$ & $7.6(7.6,7.7)$ & $8.5(8.4,8.6)$ & $9.0(8.9,9.1)$ \\
\hline \multicolumn{6}{|l|}{ Sport modality } \\
\hline Endurance & $6.2(6.1,6.3)$ & $6.7(6.7,6.8)$ & $7.6(7.6,7.7)$ & $8.5(8.5,8.6)$ & $9.1(9.0,9.1)$ \\
\hline Velocity/power & $6.3(6.2,6.4)$ & $6.8(6.8,6.9)$ & $7.7(7.7,7.8)$ & $8.6(8.5,8.7)$ & $9.1(9.0,9.2)$ \\
\hline Team sports & $6.3(6.2,6.3)$ & $6.8(6.7,6.8)$ & $7.7(7.6,7.8)$ & $8.5(8.5,8.6)$ & $9.1(9.0,9.1)$ \\
\hline
\end{tabular}


Table 4. Phase Angle reference percentiles for women.

\begin{tabular}{|c|c|c|c|c|c|}
\hline Sport Discipline & 5 th $(95 \%$ CI $)$ & 15th $(95 \% \mathrm{CI})$ & 50th $(95 \% \mathrm{CI})$ & 85th $(95 \%$ CI) & 95th $(95 \% \mathrm{CI})$ \\
\hline Athletics & $5.4(5.3,5.5)$ & $5.9(5.8,6.0)$ & $6.8(6.7,6.8)$ & $7.7(7.6,7.8)$ & $8.2(8.1,8.3)$ \\
\hline Badminton & $5.4(5.3,5.5)$ & $5.9(5.8,6.0)$ & $6.8(6.8,6.9)$ & $7.7(7.6,7.8)$ & $8.2(8.1,8.4)$ \\
\hline Basketball & $5.4(5.3,5.5)$ & $5.9(5.9,6.0)$ & $6.9(6.8,6.9)$ & $7.7(7.6,7.8)$ & $8.2(8.1,8.3)$ \\
\hline Boxing & $5.4(5.3,5.5)$ & $5.9(5.9,6.0)$ & $6.9(6.8,7.0)$ & $7.7(7.6,7.9)$ & $8.3(8.1,8.4)$ \\
\hline CrossFit & $5.3(5.2,5.4)$ & $5.9(5.8,6.0)$ & $6.8(6.8,6.9)$ & $7.7(7.6,7.8)$ & $8.2(8.1,8.3)$ \\
\hline Gymnastics & $5.4(5.3,5.5)$ & $5.9(5.9,6.0)$ & $6.8(6.8,6.9)$ & $7.8(7.7,7.9)$ & $8.3(8.1,8.4)$ \\
\hline Handball & $5.4(5.3,5.5)$ & $5.9(5.8,5.9)$ & $6.8(6.7,6.9)$ & $7.7(7.6,7.8)$ & $8.2(8.1,8.4)$ \\
\hline Judo & $5.4(5.3,5.5)$ & $5.9(5.8,5.9)$ & $6.8(6.7,6.9)$ & $7.8(7.7,7.9)$ & $8.3(8.1,8.4)$ \\
\hline Karate & $5.4(5.4,5.5)$ & $5.9(5.9,6.0)$ & $6.8(6.8,6.9)$ & $7.7(7.6,7.8)$ & $8.2(8.1,8.4)$ \\
\hline Kick-boxing & $5.4(5.4,5.5)$ & $5.9(5.9,6.0)$ & $6.8(6.8,6.9)$ & $7.7(7.6,7.8)$ & $8.2(8.1,8.3)$ \\
\hline Marathon & $5.3(5.2,5.4)$ & $5.9(5.9,6.0)$ & $6.7(6.7,6.8)$ & $7.7(7.6,7.8)$ & $8.2(8.1,8.3)$ \\
\hline Pentathlon & $5.4(5.4,5.5)$ & $5.9(5.9,6.0)$ & $6.8(6.8,6.9)$ & $7.7(7.6,7.8)$ & $8.2(8.1,8.3)$ \\
\hline Rowing & $5.4(5.4,5.5)$ & $5.9(5.9,6.0)$ & $6.9(6.8,7.0)$ & $7.8(7.7,7.9)$ & $8.3(8.1,8.4)$ \\
\hline Soccer & $5.4(5.3,5.5)$ & $5.9(5.8,5.9)$ & $6.8(6.8,6.9)$ & $7.7(7.6,7.8)$ & $8.2(8.1,8.4)$ \\
\hline Swimming & $5.4(5.4,5.5)$ & $5.9(5.9,6.0)$ & $6.8(6.8,6.9)$ & $7.7(7.7,7.8)$ & $8.2(8.1,8.4)$ \\
\hline Tennis & $5.3(5.4,5.5)$ & $5.9(5.9,6.0)$ & $6.8(6.8,6.9)$ & $7.7(7.6,7.8)$ & $8.2(8.1,8.4)$ \\
\hline Triathlon & $5.4(5.3,5.5)$ & $5.9(5.9,6.0)$ & $6.8(6.8,6.9)$ & $7.8(7.7,7.9)$ & $8.3(8.1,8.4)$ \\
\hline Volleyball & $5.4(5.4,5.6)$ & $5.9(5.9,6.0)$ & $6.8(6.7,6.9)$ & $7.7(7.6,7.8)$ & $8.2(8.1,8.3)$ \\
\hline Waterpolo & $5.4(5.4,5.6)$ & $5.9(5.8,5.9)$ & $6.8(6.8,6.9)$ & $7.8(7.7,7.9)$ & $8.3(8.2,8.4)$ \\
\hline \multicolumn{6}{|l|}{ Sport modality } \\
\hline Endurance & $5.3(5.2,5.4)$ & $5.9(5.8,5.9)$ & $6.8(6.7,6.9)$ & $7.7(7.7,7.8)$ & $8.2(8.2,8.3)$ \\
\hline Velocity/power & $5.5(5.4,5.6)$ & $6.0(5.9,6.1)$ & $6.8(6.6,6.7)$ & $7.7(7.6,7.7)$ & $8.2(8.1,8.3)$ \\
\hline Team sports & $5.4(5.3,5.5)$ & $6.0(5.9,6.1)$ & $6.8(6.8,6.9)$ & $7.7(7.6,7.8)$ & $8.3(8.2,8.3)$ \\
\hline
\end{tabular}

\section{Discussion}

The present study aimed to derive phase angle reference percentiles for athletes of both sexes and involved in different sports. To the best of our knowledge, this is the first study that provides normative values for phase angle in an athletic population, which until now were only available for the general and elderly population $[19,20]$.

The results of this study showed that regardless of sports modality, male athletes have a higher phase angle than their female counterparts. These results are in congruence with previous investigations conducted in the general population and in former athletes $[15,19]$. The biological mechanism for this observation may be due to the positive correlation of phase angle with muscle mass and the intra-to-extracellular water ratio [12,29], two parameters generally higher in male subjects [30]. Since phase angles differ within a sport by player position and role [31], it becomes difficult to compare values across sports disciplines without carefully considering these specific-factors. Differences in athletes' phase angle among different game roles, can be due to the requirements of the specific position that influences specific body composition features, especially in team sports [32]. To mitigate this challenge, comparisons between sports are often made classifying the athletes by type of sport activity, such as endurance, velocity/power, and team sports [1,24]. Between sport classifications, athletes of both sexes involved in endurance sports retained a lower phase angle compared to those engaged in velocity/power and team sports. The difference in phase angles across these sports modalities is possibly due to the lower muscle mass required for endurance compared to sports where strength and power are necessary [1]. However, the magnitude of the differences was small and further speculation could be misleading in this context. Similarly, endurance athletes of both sexes exhibited lower FFMI than other categories. This finding is probably due to more FFM present in velocity/power or team sports athletes for who the sport demand is typically anaerobic. In fact, some FFM compartments such as muscle tissue are particularly important for the glycolytic mechanisms of energy production [33].

This study reported the 5th, 15th, 50th, 85th, and 95th reference percentiles for athletes' phase angles by sex and sport. To aid application of the newly developed percentiles, we provide an example for a male endurance athlete with a phase angle of $6.8^{\circ}$. Table 3 shows 
that the estimate for the 5 th percentile is $6.2^{\circ}\left(95 \%\right.$ CI: 6.1 to $\left.6.3^{\circ}\right)$, the estimate for the 15th percentile is $6.7^{\circ}\left(95 \%\right.$ CI: 6.7 to $\left.6.8^{\circ}\right)$, and the estimate for the 50th percentile is $7.6^{\circ}$ ( $95 \%$ CI: 7.6 to $7.7^{\circ}$ ). Thus, the phase angle of this hypothetical male endurance athlete falls in the bottom half of the distribution but above the lowest $5 \%$ of that distribution, with an estimated value close to the 15 th percentile for his sport category. Since phase angle usually decreases after a preliminary time period $[34,35]$ due to the higher initial training load, this endurance athlete may undergo a decrease in phase angle beyond the 15th percentile over the season. In this study, BIA was performed during the main time of competition of the in-season period. An ideal measurement during the in-season period should stay above the 50th percentile for an athlete who is healthy and in optimal physical condition to tackle this phase of the season. Given that phase angle primarily reflects cellular health and hydration and muscle mass and its quality, nutritional support strategies should be considered, especially in athletes with low phase angle values [36-38].

The problem of recognizing exercisers who, having body composition characteristics similar to those of athletes, would benefit from specific prediction formulas for athletes even if they do not fall into this category, has recently been discussed [18]. In this regard, evaluating phase angle as a pre-screening biomarker may help to identify subjects with bioelectrical and body composition characteristics similar to the athletic population rather than to those of the general population. For example, while Mattiello et al. [19] identified a phase angle at the 50th percentile of $7.0^{\circ}$ for an adult male belonging to the general population, in this study the 50th percentile of a male athlete is around $7.7^{\circ}$. The same scenario occurs for female athletes where higher mean values than the general healthy population have previously been identified [19]. However, previous studies have shown how exercisers can still have phase angle values similar to those of an athlete $[4,39]$. Therefore, the phase angle reference values provided in this study can help practitioners understand when a subject from the general population may still have body composition characteristics similar to those of an athlete. Along these lines, future research is needed to develop phase angle cut-off values useful to identify when a BIA-based athlete-specific equation should be used to estimate body composition even in subjects belonging to the general population.

A strength of this study is the database consisting of a large number of athletes measured during the in-season phase. This is important because body composition and as a result phase angles change across the competitive season phases $[34,35]$. Some limitations are present in this study. First, we have not been able to provide reference values for young athletes, in which an increase in the phase angle is mainly dictated by the state of maturity that acts by modifying the characteristics of body composition $[7,40]$. In this regard, future research should fill this gap by including youth groups and measuring phase angle and maturity offset. Second, our outcomes were obtained from the use of a foot-to-hand technology (BIA 101, Akern, Florence, Italy), and a $50 \mathrm{kHz}$ sampling frequency. Therefore, given the lack of agreement between BIA technologies and sampling frequencies [41-43], the current findings cannot be extended to different technologies (e.g., BIA in standing position) and sampling frequencies. Lastly, although the use of empirical Bayesian framework allowed us to 'share' information across sports with lower number of participants, measures of sports disciplines with high sample sizes may have an outsized influence on the estimates of the smaller sports. However, we considered three large group of sport modalities in order to improve the quality of the athletes' classification when assessing phase angle in research as well as in the field context.

\section{Conclusions}

This study derived phase angle normative values for male and female athletes of different sports. Considering the usefulness of phase angle as a marker of a healthier body composition profile and performance, coaches and practitioners will benefit from using these sex and sports specific reference percentiles in assessing and tracking athletes over a season. These findings will also help to establish directions for future research in sports practice. 
Author Contributions: Conceptualization, F.C., L.B.S. and A.M.S.; data curation, F.C., J.C.K., G.M. (Giovanni Melchiorri), A.A., S.T., G.M. (Gabriele Mascherini), C.P., L.B.S. and A.M.S.; formal analysis, D.M.T., T.M., K.W., N.C., D.B. and T.M.; methodology, L.B.S. and A.M.S.; project administration, A.M.S.; supervision, A.M.S.; writing—original draft, F.C. and A.M.S.; writing—review and editing, all authors. All authors have read and agreed to the published version of the manuscript.

Funding: This research received no external funding.

Institutional Review Board Statement: All procedures were approved by the bioethics committee of the University of Bologna and were conducted in accordance with the declaration of Helsinki for human studies (Ethical Approval Code: 25027; dated 13 March 2017).

Informed Consent Statement: Informed consent was obtained from all subjects involved in the study.

Data Availability Statement: Data can be obtained from Francesco Campa on francesco.campa3@unibo.it.

Acknowledgments: The authors express their gratitude to all the participants involved in this study.

Conflicts of Interest: The authors declare no conflict of interest.

\section{References}

1. Silva, A.M. Structural and functional body components in athletic health and performance phenotypes. Eur. J. Clin. Nutr. 2019, 73, 215-224. [CrossRef]

2. Toselli, S.; Campa, F. Anthropometry and Functional Movement Patterns in Elite Male Volleyball Players of Different Competitive Levels. J. Strength Cond. Res. 2017, 32, 2601-2611. [CrossRef] [PubMed]

3. Brocherie, F.; Girard, O.; Forchino, F.; Al Haddad, H.; Dos Santos, G.A.; Millet, G.P. Relationships between anthropometric measures and athletic performance, with special reference to repeated-sprint ability, in the Qatar national soccer team. J. Sports Sci. 2014, 32, 1243-1254. [CrossRef]

4. Campa, F.; Piras, A.; Raffi, M.; Trofè, A.; Perazzolo, M.; Mascherini, G.; Toselli, S. The Effects of Dehydration on Metabolic and Neuromuscular Functionality During Cycling. Int. J. Environ. Res. Public Health 2020, 17, 1161. [CrossRef] [PubMed]

5. Nuccio, R.P.; Barnes, K.A.; Carter, J.M.; Baker, L.B. Fluid Balance in Team Sport Athletes and the Effect of Hypohydration on Cognitive, Technical, and Physical Performance. Sports Med. 2017, 47, 1951-1982. [CrossRef] [PubMed]

6. Cheuvront, S.N.; Kenefick, R.W. Dehydration: Physiology, assessment, and performance effects. Compr. Physiol. 2014, 4, 257-285. [CrossRef] [PubMed]

7. Campa, F.; Toselli, S.; Mazzilli, M.; Gobbo, L.A.; Coratella, G. Assessment of Body Composition in Athletes: A Narrative Review of Available Methods with Special Reference to Quantitative and Qualitative Bioimpedance Analysis. Nutrients 2021, 13, 1620. [CrossRef] [PubMed]

8. Lukaski, H.; Raymond-Pope, C.J. New Frontiers of Body Composition in Sport. Int. J. Sports Med. 2021, 42, 588-601. [CrossRef] [PubMed]

9. Coratella, G.; Campa, F.; Matias, C.N.; Toselli, S.; Koury, J.C.; Andreoli, A.; Sardinha, L.S.B.; Silva, A.M. Generalized bioelectric impedance-based equations underestimate body fluids in athletes. Scand. J. Med. Sci. Sports 2021, 31, 2123-2132. [CrossRef]

10. Campa, F.; Matias, C.N.; Marini, E.; Heymsfield, S.B.; Toselli, S.; Sardinha, L.B.; Silva, A.M. Identifying athlete body fluid changes during a competitive season with bioelectrical impedance vector analysis. Int. J. Sports Physiol. Perform. 2020, 15, 361-367. [CrossRef]

11. Norman, K.; Stobaus, N.; Pirlich, M.; Bosy-Westphal, A. Bioelectrical phase angle and impedance vector analysis-Clinical relevance and applicability of impedance parameters. Clin. Nutr. 2012, 31, 854-861. [CrossRef] [PubMed]

12. Campa, F.; Silva, A.M.; Matias, C.N.; Monteiro, C.P.; Paoli, A.; Nunes, J.P.; Talluri, J.; Lukaski, H.; Toselli, S. Body Water Content and Morphological Characteristics Modify Bioimpedance Vector Patterns in Volleyball, Soccer, and Rugby Players. Int. J. Environ. Res. Public Health 2020, 17, 6604. [CrossRef] [PubMed]

13. Gonzalez, M.C.; Barbosa-Silva, T.G.; Bielemann, R.M.; Gallagher, D.; Heymsfield, S.B. Phase angle and its determinants in healthy subjects: Influence of body composition. Am. J. Clin. Nutr. 2016, 103, 712-716. [CrossRef] [PubMed]

14. Francisco, R.; Matias, C.N.; Santos, D.A.; Campa, F.; Minderico, C.S.; Rocha, P.; Heymsfield, S.B.; Lukaski, H.; Sardinha, L.B.; Silva, A.M. The Predictive Role of Raw Bioelectrical Impedance Parameters in Water Compartments and Fluid Distribution Assessed by Dilution Techniques in Athletes. Int. J. Environ. Res. Public Health 2020, 17, 759. [CrossRef] [PubMed]

15. Matias, C.N.; Campa, F.; Nunes, C.L.; Francisco, R.; Jesus, F.; Cardoso, M.; Valamatos, M.J.; Homens, P.M.; Sardinha, L.B.; Martins, P.; et al. Phase Angle Is a Marker of Muscle Quantity and Strength in Overweight/Obese Former Athletes. Int. J. Environ. Res. Public Health 2021, 18, 6649. [CrossRef]

16. Nabuco, H.C.G.; Silva, A.M.; Sardinha, L.B.; Rodrigues, F.B.; Tomeleri, C.M.; Ravagnani, F.C.P.; Cyrino, E.S.; Ravagnani, C.F.C. Phase Angle is Moderately Associated with Short-term Maximal Intensity Efforts in Soccer Players. Int. J. Sports Med. 2019, 40, 739-743. [CrossRef] [PubMed] 
17. Martins, P.C.; Teixeira, A.S.; Guglielmo, L.G.A.; Francisco, J.S.; Silva, D.A.S.; Nakamura, F.Y.; Lima, L.R.A. de Phase Angle Is Related to $10 \mathrm{~m}$ and $30 \mathrm{~m}$ Sprint Time and Repeated-Sprint Ability in Young Male Soccer Players. Int. J. Environ. Res. Public Health 2021, 18, 4405. [CrossRef]

18. Campa, F.; Coratella, G. Athlete or non-athlete? This is the question in body composition. Front. Physiol. 2021, $12,814572$. [CrossRef]

19. Mattiello, R.; Amaral, M.A.; Mundstock, E.; Ziegelmann, P.K. Reference values for the phase angle of the electrical bioimpedance: Systematic review and meta-analysis involving more than 250,000 subjects. Clin. Nutr. 2020, 39, 1411-1417. [CrossRef]

20. Reljic, D.; Zarafat, D.; Jensen, B.; Herrmann, H.J.; Neurath, M.F.; Konturek, P.C.; Zopf, Y. Phase angle and vector analysis from multifrequency segmental bioelectrical impedance analysis: New reference data for older adults. J. Physiol. Pharmacol. 2020, 71 491-499. [CrossRef]

21. Barbosa-Silva, M.C.G.; Barros, A.J.D.; Wang, J.; Heymsfield, S.B.; Pierson Richard, N.J. Bioelectrical impedance analysis: Population reference values for phase angle by age and sex. Am. J. Clin. Nutr. 2005, 82, 49-52. [CrossRef]

22. Kuchnia, A.J.; Teigen, L.M.; Cole, A.J.; Mulasi, U.; Gonzalez, M.C.; Heymsfield, S.B.; Vock, D.M.; Earthman, C.P. Phase Angle and Impedance Ratio: Reference Cut-Points From the United States National Health and Nutrition Examination Survey 1999-2004 From Bioimpedance Spectroscopy Data. JPEN J. Parenter. Enteral Nutr. 2017, 41, 1310-1315. [CrossRef] [PubMed]

23. Bosy-Westphal, A.; Danielzik, S.; Dörhöfer, R.-P.; Later, W.; Wiese, S.; Müller, M.J. Phase angle from bioelectrical impedance analysis: Population reference values by age, sex, and body mass index. JPEN J. Parenter. Enteral Nutr. 2006, 30, 309-316. [CrossRef] [PubMed]

24. Campa, F.; Matias, C.; Gatterer, H.; Toselli, S.; Koury, J.C.; Andreoli, A.; Melchiorri, G.; Sardinha, L.B.; Silva, A.M. Classic Bioelectrical Impedance Vector Reference Values for Assessing Body Composition in Male and Female Athletes. Int. J. Environ. Res. Public Health 2019, 16, 5066. [CrossRef] [PubMed]

25. Campa, F.; Levi Micheli, M.; Pompignoli, M.; Cannataro, R.; Gulisano, M.; Toselli, S.; Greco, G.; Coratella, G. The Influence of Menstrual Cycle on Bioimpedance Vector Patterns, Performance, and Flexibility in Elite Soccer Players. Int. J. Sports Physiol. Perform. 2021, 17, 58-66. [CrossRef] [PubMed]

26. Matias, C.N.; Campa, F.; Santos, D.A.; Lukaski, H.; Sardinha, L.B.; Silva, A.M. Fat-free Mass Bioelectrical Impedance Analysis Predictive Equation for Athletes using a 4-Compartment Model. Int. J. Sports Med. 2021, 42, 27-32. [CrossRef]

27. Casella, G. An Introduction to Empirical Bayes Data Analysis. Am. Stat. 1985, 39, 83-87. [CrossRef]

28. Hopkins, W.G.; Marshall, S.W.; Batterham, A.M.; Hanin, J. Progressive statistics for studies in sports medicine and exercise science. Med. Sci. Sports Exerc. 2009, 41, 3-13. [CrossRef]

29. Marini, E.; Campa, F.; Buffa, R.; Stagi, S.; Matias, C.N.; Toselli, S.; Sardinha, L.B.; Silva, A.M. Phase angle and bioelectrical impedance vector analysis in the evaluation of body composition in athletes. Clin. Nutr. 2020, 39, 447-454. [CrossRef]

30. Heymsfield, S.; Lohman, T.; Wang, Z.; Going, S. Human Body Composition, 2nd ed.; Human Kinetics: Champaign, IL, USA, 2005.

31. Bongiovanni, T.; Mascherini, G.; Genovesi, F.; Pasta, G.; Iaia, F.M.; Trecroci, A.; Ventimiglia, M.; Alberti, G.; Campa, F. Bioimpedance Vector References Need to Be Period-Specific for Assessing Body Composition and Cellular Health in Elite Soccer Players: A Brief Report. J. Funct. Morphol. Kinesiol. 2020, 5, 73. [CrossRef]

32. Till, K.; Scantlebury, S.; Jones, B. Anthropometric and Physical Qualities of Elite Male Youth Rugby League Players. Sports Med. 2017, 47, 2171-2186. [CrossRef] [PubMed]

33. Durkalec-Michalski, K.; Nowaczyk, P.M.; Podgórski, T.; Kusy, K.; Osiński, W.; Jeszka, J. Relationship between body composition and the level of aerobic and anaerobic capacity in highly trained male rowers. J. Sports Med. Phys. Fitness 2019, 59, 1526-1535. [CrossRef] [PubMed]

34. Reis, J.F.; Matias, C.N.; Campa, F.; Morgado, J.P.; Franco, P.; Quaresma, P.; Almeida, N.; Curto, D.; Toselli, S.; Monteiro, C.P. Bioimpedance Vector Patterns Changes in Response to Swimming Training: An Ecological Approach. Int. J. Environ. Res. Public Health 2020, 17, 4851. [CrossRef] [PubMed]

35. Mascherini, G.; Gatterer, H.; Lukaski, H.; Burtscher, M.; Galanti, G. Changes in hydration, body-cell mass and endurance performance of professional soccer players through a competitive season. J. Sports Med. Phys. Fitness 2015, 55, 749-755.

36. Barrea, L.; Muscogiuri, G.; Pugliese, G.; Laudisio, D.; de Alteriis, G.; Graziadio, C.; Colao, A.; Savastano, S. Phase Angle as an Easy Diagnostic Tool of Meta-Inflammation for the Nutritionist. Nutrients 2021, 13, 1446. [CrossRef]

37. Barrea, L.; Muscogiuri, G.; Laudisio, D.; Di Somma, C.; Salzano, C.; Pugliese, G.; de Alteriis, G.; Colao, A.; Savastano, S. Phase Angle: A Possible Biomarker to Quantify Inflammation in Subjects with Obesity and 25(OH)D Deficiency. Nutrients 2019, 11, 1747. [CrossRef]

38. Roberts, J.; Zinchenko, A.; Suckling, C.; Smith, L.; Johnstone, J.; Henselmans, M. The short-term effect of high versus moderate protein intake on recovery after strength training in resistance-trained individuals. J. Int. Soc. Sports Nutr. 2017, 14, 44. [CrossRef]

39. Paoli, A.; Casolo, A.; Saoncella, M.; Bertaggia, C.; Fantin, M.; Bianco, A.; Marcolin, G.; Moro, T. Effect of an Endurance and Strength Mixed Circuit Training on Regional Fat Thickness: The Quest for the "Spot Reduction". Int. J. Environ. Res. Public Health 2021, 18, 3845. [CrossRef]

40. Koury, J.C.; de Oliveira-Junior, A.V.; Portugal, M.R.C.; de Oliveira, K.J.F.; Donangelo, C.M. Bioimpedance parameters in adolescent athletes in relation to bone maturity and biochemical zinc indices. J. Trace Elem. Med. Biol. 2018, 46, 26-31. [CrossRef] 
41. Silva, A.M.; Matias, C.N.; Nunes, C.L.; Santos, D.A.; Marini, E.; Lukaski, H.C.; Sardinha, L.B. Lack of agreement of in vivo raw bioimpedance measurements obtained from two single and multi-frequency bioelectrical impedance devices. Eur. J. Clin. Nutr. 2019, 73, 1077-1083. [CrossRef]

42. Stratton, M.T.; Smith, R.W.; Harty, P.S.; Rodriguez, C.; Johnson, B.A.; Dellinger, J.R.; Williams, A.D.; White, S.J.; Benavides, M.L.; Tinsley, G.M. Longitudinal agreement of four bioimpedance analyzers for detecting changes in raw bioimpedance during purposeful weight gain with resistance training. Eur. J. Clin. Nutr. 2021, 75, 1060-1068. [CrossRef] [PubMed]

43. Dellinger, J.R.; Johnson, B.A.; Benavides, M.L.; Moore, M.L.; Stratton, M.T.; Harty, P.S.; Siedler, M.R.; Tinsley, G.M. Agreement of bioelectrical resistance, reactance, and phase angle values from supine and standing bioimpedance analyzers. Physiol. Meas. 2021, 42, 035003. [CrossRef] [PubMed] 